\title{
Perioperative complications of adrenalectomy - 12 years of experience from a single center/teaching hospital and literature review
}

Michał Aporowicz, Paweł Domosławski, Piotr Czopnik, Krzysztof Sutkowski, Krzysztof Kaliszewski

$1^{\text {st }}$ Department and Clinic of General, Gastroenterological and Endocrine Surgery, Wroclaw Medical University, Wroclaw, Poland

Submitted: 22 March 2016

Accepted: 15 August 2016

Arch Med Sci 2018; 14, 5: 1010-1019

DOI: https://doi.org/10.5114/aoms.2018.77257

Copyright $\odot 2018$ Termedia \& Banach

\section{Abstract}

Introduction: The perioperative complication rate of adrenalectomy varies between $1.7 \%$ and $30.7 \%$ in the medical literature. This study presents outcomes of adrenalectomy in our center and tries to point out risk factors for perioperative problems.

Material and methods: We retrospectively analyzed all patients who underwent adrenalectomy in our department from January 2004 to June 2015. Patient's sex, indication for procedure, tumor laterality, surgical approach and surgeon's case volume were taken into consideration as possible risk factors for complications.

Results: There were 177 adrenalectomies performed on 170 patients. We reported 18 (10.2\%) perioperative complications, $12(6.8 \%)$ surgical and $6(3.4 \%)$ medical. Laparotomy was a significant risk factor for medical $(p<0.01)$ and overall problems $(p=0.02)$. Operations more expansive than just adrenalectomy were associated with higher risk of medical complications $(p=0.01)$. Procedures performed by surgeons with higher volume were associated with smaller risk of medical complications $(p<0.01)$. Right and left adrenalectomies seem to be related to different kinds of risk - bleeding on the right, injury of surrounding structures on the left $(p=0.05)$. Patient's sex, indication for procedure, bilateral procedure and side of operation were not statistically significant risk factors for complications.

Conclusions: Adrenal glands are surrounded by various anatomic structures (colon, pancreas, spleen, diaphragm) that may be injured during adrenalectomy. Complications following a laparoscopic procedure may arise from the use of monopolar coagulation and the patient's position on the operating table. High insufflation pressure during retroperitoneoscopic procedures may cause subcutaneous emphysema.

Key words: complications, laparoscopy, adrenalectomy, teaching, adrenal gland neoplasms.

\section{Introduction}

Adrenalectomy is considered to be a relatively safe surgical procedure. However, its perioperative complication rate varies between $1.7 \%$ and $30.7 \%[1,2]$. In the past many features were assessed as possible risk factors for complications. Patient's sex, indication for procedure, tumor laterality, surgical approach and surgeon's case volume were among them. This study presents outcomes of adrenalectomy in our center and

\author{
Corresponding author: \\ Michał Aporowicz \\ Department and Clinic \\ of General, \\ Gastroenterological \\ and Endocrine Surgery \\ Wroclaw Medical \\ University \\ 66 Marii Skłodowskiej-Curie St \\ 50-369 Wroclaw, Poland \\ Phone: +48 505349825 , \\ +48717842162 \\ E-mail: micapo@interia.pl
}


tries to point out some significant risk factors for perioperative problems.

\section{Material and methods}

We retrospectively analyzed all patients who underwent adrenalectomy at the $1^{\text {st }}$ Department and Clinic of General, Gastroenterological and Endocrine Surgery of Wroclaw Medical University in the period from January 2004 to June 2015. All patients' data were stored in a clinical database. To identify risk factors for complications we compared their rates in different groups of patients. The $\chi^{2}$ test and Spearman correlation were used to calculate $p$-values. A $p$-value $<0.05$ was considered as statistically significant. All tests were two-tailed.

The number of performed procedures in each year, sex and age of patients, indication for adrenalectomy, surgical approach, side of procedure and histopathological report are summarized in Table I. We treated laparotomy and conversion equally in analysis of complications. Simultaneous additional abdominal procedures were performed in 13 (7.3\%) cases. When no material was obtained for histopathological study, it was due to extensive adhesions or associated bleeding (scheduled resection was aborted, but the procedure was associated with the same possible complications as adrenalectomy; therefore we included 4 such cases in our analysis).

The techniques for open and laparoscopic approaches were as follows. For open adrenalectomy the patient was placed in a supine position. Following induction of general anesthesia, the operative field was prepared and draped. A transverse subcostal (Kocher) incision was made below the right or left costal arch, depending on the side of the tumor. After opening the peritoneal cavity, the parietal peritoneum was incised, mobilizing the hepatic or splenic flexure of the colon, respectively. The adrenal gland tumor was identified above the superior pole of the kidney and dissected from surrounding structures. The adrenal vein was doubly ligated and transected between sutures. Dissection was continued further around the tumor, until it had been completely freed, then the specimen was removed from operative field. After inspection of the hemostasis, the abdominal cavity was drained and closed layer by layer. A sterile dressing was placed on the operative wound.

For laparoscopic adrenalectomy the patient was put under general anesthesia, then placed in a lateral position, lying on the side opposite to the tumor. The Veress needle was introduced to the peritoneal cavity about $3-4 \mathrm{~cm}$ below the costal arch, medially to the anterior axillary line, on the side of the tumor. The peritoneal cavity was then insufflated with carbon dioxide to $12 \mathrm{~mm} \mathrm{Hg}$ and the first port with a 30-degree camera was introduced at the same point as the needle. For left adrenalectomy 2 additional ports $(10 \mathrm{~mm}$ and $5 \mathrm{~mm}$ ) were placed below the costal arch in a linear pattern. For a right-sided procedure 3 additional ports (two $10 \mathrm{~mm}$ and $5 \mathrm{~mm}$ ) were used; an extra fourth $10 \mathrm{~mm}$ port was necessary to introduce the liver retractor. On the right side, the right triangular hepatic ligament was incised, then the parietal peritoneum incised to free the hepatic flexure of the colon. On the left side, splenorenal and colorenal ligaments were dissected and the splenic flexure was mobilized. After visualization of the adrenal tumor, it was dissected using both blunt dissection and monopolar coagulation. The adrenal vein was identified, doubly secured using metal clips and transected between them. The tumor was further dissected then removed from the abdominal cavity using a plastic bag. After inspection of the hemostasis, the abdominal cavity was drained (through the $5 \mathrm{~mm}$ port), desufflated and port sites closed. Sterile dressings were applied on port-site wounds.

\section{Results}

During the analyzed period 177 adrenalectomies were performed on 170 patients. Five patients were operated on twice and one three times. Five patients underwent two-step bilateral adrenalectomy. In 1 case there was a residual hormonally active adrenal remnant on one side and the patient required a third procedure. In the other case the previously removed tumor recurred after 2 years and the patient required a second operation on the same side; the tumor turned out to be an adrenocortical carcinoma. In our analysis these cases were treated as separate and independent procedures.

We encountered 18 (10.2\%) intra- and postoperative complications, 12 (6.8\%) surgical, directly related to the procedure, and 6 (3.4\%) medical. In some cases the problems resulted from a simultaneous abdominal procedure rather than the adrenalectomy itself. Each complication, its management, type (bleeding, lesion, others), severity (in the Clavien-Dindo classification for postoperative problems) and patient's data are presented in Table II [3].

To identify risk factors we analyzed complication rates in different groups of patients. Table III presents overall, surgical and medical problem rates. Patient's sex, indication for adrenalectomy, site of operation, method and scope of procedure as well as case volume of the performing surgeon were taken into consideration as potential risk factors. Surgical complications were further divided into: bleeding, lesions of surrounding structures and others, and their rates were com- 
Michał Aporowicz, Paweł Domosławski, Piotr Czopnik, Krzysztof Sutkowski, Krzysztof Kaliszewski

Table I. Demographic, surgical and pathologic profile of patients and procedures

\begin{tabular}{|c|c|c|c|c|}
\hline Year & Number of procedures & Side of procedure & \multicolumn{2}{|c|}{ Value } \\
\hline 2004 & 6 & Unilateral: & \multicolumn{2}{|c|}{$171(96.6 \%)$} \\
\hline 2005 & 5 & Right & \multicolumn{2}{|c|}{$79(46.2 \%)$} \\
\hline 2006 & 7 & Left & \multicolumn{2}{|c|}{$92(53.8 \%)$} \\
\hline 2007 & 8 & Simultaneous bilateral & \multicolumn{2}{|c|}{$6(3.4 \%)$} \\
\hline 2008 & 19 & Total & \multicolumn{2}{|c|}{177} \\
\hline 2009 & 18 & Histopathological report & \multicolumn{2}{|c|}{ Value } \\
\hline 2010 & 15 & $\begin{array}{l}\text { Adrenocortical } \\
\text { adenoma (ACA) }\end{array}$ & $85(48.0 \%)$ & \multirow[t]{10}{*}{ Benign: 156 (88.1\%) } \\
\hline 2011 & 13 & $\begin{array}{l}\text { Nodular hyperplasia } \\
(\mathrm{NH})\end{array}$ & $22(12.4 \%)$ & \\
\hline 2012 & 14 & $\begin{array}{l}\text { ACA/NH (distinction } \\
\text { impossible) }\end{array}$ & $3(1.7 \%)$ & \\
\hline 2013 & 31 & Pheochromocytoma & $19(10.7 \%)$ & \\
\hline 2014 & 22 & No pathology & $7(4.0 \%)$ & \\
\hline 2015 (until June) & 19 & Myelolipoma & 7 (4.0\%) & \\
\hline Total & 177 & Hematoma & $4(2.3 \%)$ & \\
\hline Sex of patients & $N(\%)$ & Cyst & $6(3.4 \%)$ & \\
\hline Females & $126(71.2)$ & Hemangioma & $2(1.1 \%)$ & \\
\hline Males & $51(28.8)$ & Ganglioneuroma & $1(0.6 \%)$ & \\
\hline Age of patients & Value & Metastases & $12(6.8 \%)$ & \multirow[t]{4}{*}{ Malignant: 17 (9.6\%) } \\
\hline $18-19$ & $0(0.0 \%)$ & $\begin{array}{l}\text { Adrenocortical } \\
\text { carcinoma (ACC) }\end{array}$ & $3(1.7 \%)$ & \\
\hline $20-29$ & $4(2.3 \%)$ & $\begin{array}{l}\text { Lymphoma (diffuse } \\
\text { large B cell I) }\end{array}$ & $1(0.6 \%)$ & \\
\hline $30-39$ & $11(6.2 \%)$ & Schwannoma & $1(0.6 \%)$ & \\
\hline $40-49$ & $28(15.8 \%)$ & No material obtained & \multicolumn{2}{|c|}{$4(2.3 \%)^{*}$} \\
\hline $50-59$ & $67(37.9 \%)$ & Total & \multicolumn{2}{|c|}{177} \\
\hline $60-69$ & $53(29.9 \%)$ & Indication for adrenalectomy & \multicolumn{2}{|c|}{ Value } \\
\hline $70-79$ & $13(7.3 \%)$ & $\begin{array}{l}\text { Tumor, non- } \\
\text { functioning }\end{array}$ & \multicolumn{2}{|c|}{$99(55.9 \%)$} \\
\hline $80+$ & $1(0.6 \%)$ & $\begin{array}{l}\text { Cyst, non- } \\
\text { functioning }\end{array}$ & \multicolumn{2}{|c|}{$3(1.7 \%)$} \\
\hline Mean & $55.9 \pm 10.9$ & $\begin{array}{l}\text { Pheochromocytoma } \\
\text { or suspicion }\end{array}$ & \multicolumn{2}{|c|}{$24(13.6 \%)$} \\
\hline Surgical approach & Value & Cushing syndrome & \multicolumn{2}{|c|}{$18(10.2 \%)$} \\
\hline $\begin{array}{l}\text { Retroperitoneal, } \\
\text { open }\end{array}$ & $2(1.1 \%)$ & Conn syndrome & \multicolumn{2}{|c|}{$19(10.7 \%)$} \\
\hline Laparotomy & $52(29.4 \%)$ & $\begin{array}{l}\text { Cushing and Conn } \\
\text { syndrome }\end{array}$ & \multicolumn{2}{|c|}{$1(0.6 \%)$} \\
\hline Laparoscopy & $105(59.3 \%)$ & $\begin{array}{l}\text { Metastases or } \\
\text { suspicion }\end{array}$ & \multicolumn{2}{|c|}{$12(6.8 \%)$} \\
\hline $\begin{array}{l}\text { Laparoscopy with } \\
\text { conversion }\end{array}$ & $9(5.1 \%)$ & Recurrent tumor & \multicolumn{2}{|c|}{$1(0.6 \%)$} \\
\hline Retroperitoneoscopic & $9(5.1 \%)$ & Total & \multicolumn{2}{|c|}{177} \\
\hline Total & 177 & & & \\
\hline
\end{tabular}




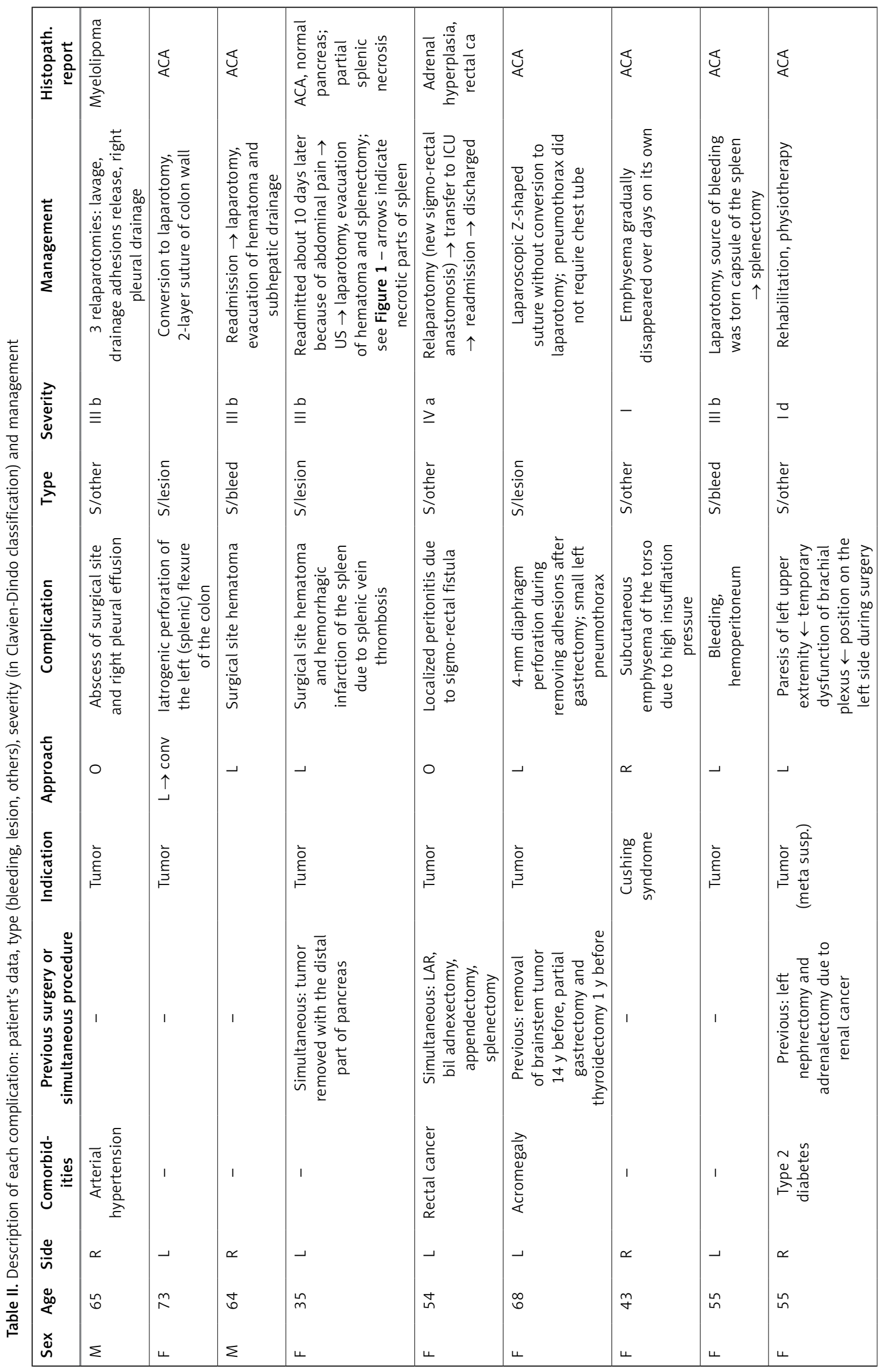




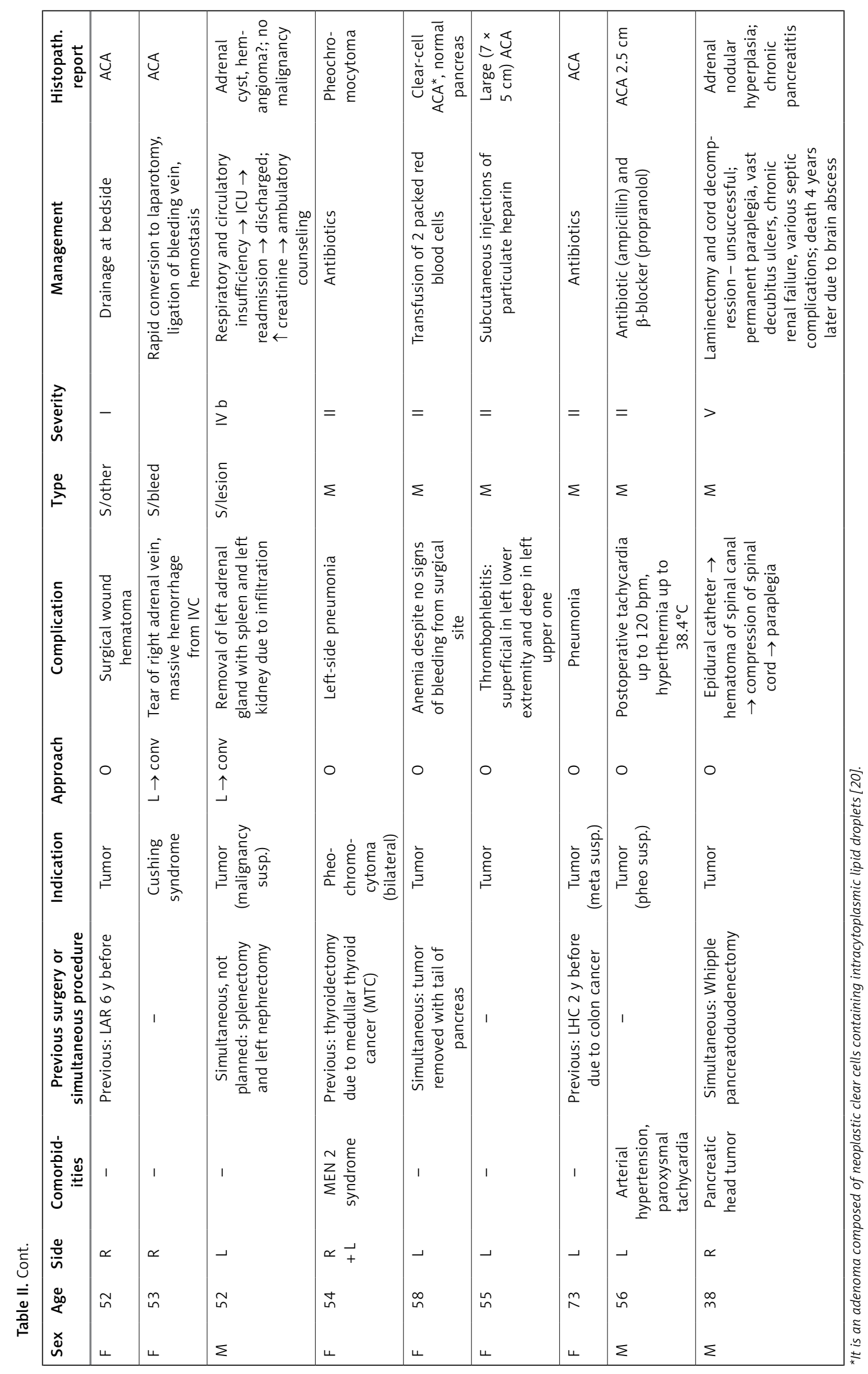


Table III. The analysis of possible risk factors for complications

\begin{tabular}{|c|c|c|c|c|c|}
\hline Variable & $\begin{array}{l}\text { All patients } \\
\text { (1) }\end{array}$ & $\begin{array}{l}\text { All complica- } \\
\text { tions ( } 2)\end{array}$ & $\begin{array}{l}\text { Surgical com- } \\
\text { plications (3) }\end{array}$ & $\begin{array}{l}\text { Medical com- } \\
\text { plications (4) }\end{array}$ & $\begin{array}{l}\text { Statistical } \\
\text { significance }\end{array}$ \\
\hline Sex: & & & & & $p=0.92(2)$ \\
\hline Female & $126(71.2 \%)$ & $13(10.3 \%)$ & $9(7.1 \%)$ & $4(3.2 \%)$ & $p=0.76(3)$ \\
\hline Male & $51(28.8 \%)$ & $5(9.8 \%)$ & $3(5.9 \%)$ & $2(3.9 \%)$ & $p=0.80(4)$ \\
\hline \multicolumn{6}{|l|}{ Indication: } \\
\hline Tumor or cyst & $102(57.6 \%)$ & $13(12.7 \%)$ & $9(8.8 \%)$ & $4(3.9 \%)$ & $p=0.41(2)$ \\
\hline Hyperactivity & $62(35.0 \%)$ & $4(6.5 \%)$ & $2(3.2 \%)$ & $2(3.2 \%)$ & $p=0.38(3)$ \\
\hline Metastases/recidivation & $13(7.4 \%)$ & $1(7.7 \%)$ & $1(7.7 \%)$ & 0 & $p=0.76(4)$ \\
\hline Uni-/bilateral: & & & & & $p=0.59(2)$ \\
\hline Unilateral & $171(96.6 \%)$ & $17(9.9 \%)$ & $12(7.0 \%)$ & $5(2.8 \%)$ & $p=0.50(3)$ \\
\hline Bilateral & $6(3.4 \%)$ & $1(16.7 \%)$ & 0 & $1(16.7 \%)$ & $p=0.07(4)$ \\
\hline Laterality (for unilateral): & & & & & $p=0.66(2)$ \\
\hline Right & $79(46.2 \%)$ & $7(8.9 \%)$ & $6(7.6 \%)$ & $1(1.3 \%)$ & $p=0.78(3)$ \\
\hline Left & $92(53.8 \%)$ & $10(10.9 \%)$ & $6(6.5 \%)$ & $4(4.3 \%)$ & $p=0.23(4)$ \\
\hline \multicolumn{6}{|l|}{ Method: } \\
\hline Laparotomy or conversion & $61(34.5 \%)$ & $12(19.7 \%)$ & $6(9.8 \%)$ & $6(9.8 \%)$ & $p=0.02(2)\left(^{*}\right)$ \\
\hline Retroperitoneal, open & $2(1.1 \%)$ & 0 & 0 & 0 & $p=0.57(3)$ \\
\hline Laparoscopic & $105(59.3 \%)$ & $5(4.8 \%)$ & $5(4.8 \%)$ & 0 & $p<0.01(4)\left({ }^{*}\right)$ \\
\hline Retroperitoneoscopic & $9(5.1 \%)$ & $1(11.1 \%)$ & $1(11.1 \%)$ & 0 & \\
\hline Scope: & & & & & $p=0.11(2)$ \\
\hline Only adrenalectomy & $164(92.7 \%)$ & $15(9.1 \%)$ & $11(6.7 \%)$ & $4(2.4 \%)$ & $p=0.89$ (3) \\
\hline Additional procedures & $13(7.3 \%)$ & $3(23.0 \%)$ & $1(7.7 \%)$ & $2(15.4 \%)$ & $p=0.01(4)\left(^{*}\right)$ \\
\hline \multicolumn{6}{|l|}{ Operator: } \\
\hline No. 1 & $75(42.4 \%)$ & $5(6.7 \%)$ & $4(5.3 \%)$ & $1(1.3 \%)$ & $p=0.24(2)$ \\
\hline No. 2 & 35 (19.8\%) & $5(14.3 \%)$ & $5(14.3 \%)$ & 0 & $p=0.92(3)$ \\
\hline No. 3 & $11(6.2 \%)$ & $2(18.2 \%)$ & $1(9.1 \%)$ & $1(9.1 \%)$ & $p<0.01(4)\left({ }^{*}\right)$ \\
\hline No. 4 (resident) & $10(5.6 \%)$ & 0 & 0 & 0 & $\begin{array}{c}r=-0.10 \\
p=0.72(2)\end{array}$ \\
\hline No. 5 & $10(5.6 \%)$ & $1(10.0 \%)$ & $1(10.0 \%)$ & 0 & $\begin{array}{c}r=0.31 \\
p=0.29(3)\end{array}$ \\
\hline No. 6 & $8(4.5 \%)$ & 0 & 0 & 0 & $\begin{array}{c}r=-0.22 \\
p=0.44(4)\end{array}$ \\
\hline No. 7 & $5(2.8 \%)$ & $2(40.0 \%)$ & $1(20.0 \%)$ & $1(20.0 \%)$ & $\begin{array}{l}\text { Resident vs. } \\
\text { rest: }\end{array}$ \\
\hline No. 8 & $5(2.8 \%)$ & $1(20.0 \%)$ & 0 & $1(20.0 \%)$ & $p=0.27(2)$ \\
\hline No. 9 & $4(2.3 \%)$ & 0 & 0 & 0 & $p=0.38(3)$ \\
\hline No. 10 & $3(1.7 \%)$ & 0 & 0 & 0 & $p=0.54(4)$ \\
\hline No. 11 & $3(1.7 \%)$ & 0 & 0 & 0 & \\
\hline No. 12 & $2(1.1 \%)$ & $1(50.0 \%)$ & 0 & $1(50.0 \%)$ & \\
\hline No. 13 & $2(1.1 \%)$ & $1(50.0 \%)$ & 0 & $1(50.0 \%)$ & \\
\hline No. 14 & $2(1.1 \%)$ & 0 & 0 & 0 & \\
\hline No. 15 & $1(0.6 \%)$ & 0 & 0 & 0 & \\
\hline No. 16 & $1(0.6 \%)$ & 0 & 0 & 0 & \\
\hline Laterality: & & Bleeding & Lesion & Others & $p=0.47(2)$ \\
\hline Right & 79 (46.2\%) & $2(2.5 \%)$ & $0(0.0 \%)$ & $4(5.1 \%)$ & $p=0.06$ \\
\hline Left & $92(53.8 \%)$ & $1(1.1 \%)$ & $4(4.3 \%)$ & $1(1.1 \%)$ & $\begin{array}{c}p=0.05 \\
(2 \text { vs. } 3)\left({ }^{*}\right)\end{array}$ \\
\hline
\end{tabular}




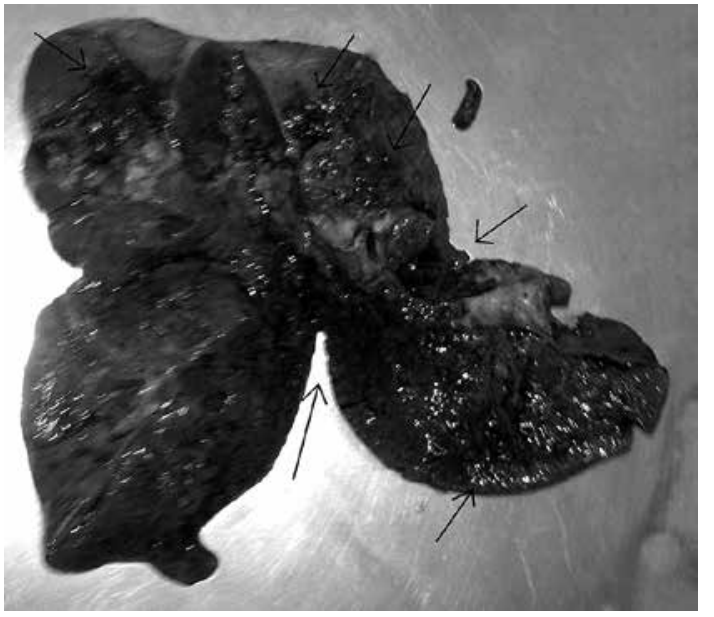

Figure 1. Postoperative specimen, splenectomy due to infarction. Arrows show necrotic parts of the spleen

pared during right- and left-side procedures. Statistically significant values were indicated with an asterisk.

In our analysis patients' sex was not a risk factor for complications. Surgical complications tended to be more common in females while medical ones more common in males. The total complication rate was similar in these groups. Differences were not statistically significant.

Type of adrenal pathology diagnosed by the referring physician was also not a risk factor. Both surgical and medical complications were observed mostly after resection of a benign, non-functioning tumor or cyst, but no differences were statistically significant.

Side of operation was not a risk factor either. All surgical problems followed unilateral procedures. Medical and overall complications were more common after bilateral adrenalectomy, but these differences were not significant.

We observed a higher rate of surgical complications after right adrenalectomy, but it was not statistically significant. Non-surgical problems seemed to be more common after the left-side procedure, also insignificantly. Overall complication rates were similar. Tumor laterality was not a risk factor for complications.

Surgical approach proved to be an important risk factor for medical and total complications. All non-surgical problems followed laparotomy or conversion. Laparotomy was also related to the highest rate of overall problems. Both differences were statistically significant. The highest rate of surgical complications was observed in the retroperitoneoscopic group, but the differences were insignificant.

Operations more expansive than simple adrenalectomy had significantly higher rate of medical complications. Surgical and overall complications were also more common after broader operations, but the differences were not significant.

In our material operations were performed by 16 different surgeons. Only medical complication rate depended on the surgeon case volume. Differences in rates of surgical and overall complications were not statistically significant. There was a weak, inversely proportional dependency between surgical case volume and total and medical complication rates, but statistically insignificant as a correlation.

Among presented surgeons there was one resident (operator no. 4), who performed 10 procedures without any type of complications. His complication rates seemed therefore lower than those of some senior surgeons, but the differences were statistically insignificant.

We compared complication rates in three subgroups of surgical complications (bleeding, lesions of surrounding structures and others) after right and left adrenalectomy. Bleeding was more common on the right side, while lesions occurred more often on the left; the differences were insignificant. When comparing bleeding vs lesions on both sides, the difference was also on the threshold of significance.

\section{Discussion}

The occurrence of perioperative complications in adrenal gland surgery varies from $1.7 \%$ to $30.7 \%$ in the medical literature $[1,2]$. Complication rates from our observations place our clinic in the middle class of surgical centers.

We did not find an association between patient's sex and complication rate either in our material or in reviewed articles [4, 5].

Many authors report that surgical and center case volumes are predictors of postoperative complications, but others report no such correlation [69]. In our material surgical case volume proved to be an important risk factor for medical complications.

The impact of participation of surgical trainees on perioperative outcomes is interesting. Adrenalectomies performed with residents or fellows take a little longer time (about $16 \mathrm{~min}$ ), regardless of operative approach. Teaching hospitals may have greater risk of complications. Other studies do not find a correlation between resident participation and perioperative morbidity. One study even found the participation of trainees to decrease the odds of complications, but failed to explain why. In our observation complication rates of residents are at least comparable to those of senior operators [8-10].

Bilateral adrenalectomy is associated with a higher complication rate (23\% vs. $15 \%$; even $26 \%$ according to Wong) $[7,8,11,12]$. In our study medical and overall complications were more common after bilateral adrenalectomy. There were no 
surgical problems following bilateral procedures, but we had only 6 of them in our material.

Most reviewed publications did not find the side of the operation to be a risk factor for risk of complications [4, 5]. However, due to asymmetry of the abdomen, left and right adrenalectomy may be associated with different types of risk. Both vascular and parenchymal structures should be considered.

The left adrenal vein is $2-4 \mathrm{~cm}$ long, passes behind the pancreas, unites with the left inferior phrenic vein and drains into the left renal vein. The right adrenal vein is shorter $(1-5 \mathrm{~mm})$ and directly enters the inferior vena cava (IVC). Both length of the right vein and its proximity to the IVC create major risk of iatrogenic injury and bleeding. Therefore it should be early ligated and divided. Loss of control of the vein may cause severe hemorrhage and require immediate IVC repair $[11,13]$. Such an event happened to our patient no. 11 - see Table II.

During transperitoneal left adrenalectomy intraoperative injury of the spleen, splenic vessels and colon is possible. The left adrenal gland is also in close proximity to the pancreatic tail, so careless dissection in this area may cause pancreatic injury leading to fistula and/or pseudocyst. The prevalence of pancreatic fistula is $2.3 \%$ according to Alesina. We encountered one iatrogenic perforation of the colon, one hemorrhagic infarction of the spleen, one diaphragm perforation and one hemoperitoneum caused by torn capsule of the spleen - see patients no. 2, 4, 6 and $8[1,5,7,12$, 14, 15].

Few studies compare outcomes of adrenalectomy between benign and malignant or secreting and non-secreting tumors. Kiernan concluded that type of pathology influences neither the complication rate nor the necessity of transfusions [14]. Porpiglia found no differences in perioperative variables between secreting vs. non-secreting and malignant vs benign tumors [5].

Pheochromocytoma may have adverse operative outcomes regardless of operative approach. Such tumors may be larger than average, more vascularized and friable. There is always a risk of both hypotensive and/or hypertensive crisis, despite preoperative preparation with adrenolytics. The most dangerous after-effects of hypertensive crisis are cardio-respiratory arrest and cerebral infarction. Early control of the adrenal vein and minimal tumor manipulation are essential for an uneventful procedure [11, 14-16].

Cushing's disease/syndrome makes adrenalectomy more difficult and increases the risk of metabolic complications and respiratory insufficiency. Due to anti-inflammatory and immune-suppressive effects of cortisol, the risk of postoperative infections increases. Inhibition of collagen synthesis and increased blood coagulability make these pa- tients susceptible to poor wound healing, deep venous thrombosis, and pulmonary embolism [12].

Adrenocortical carcinoma is quite rare but also likely to have adverse therapeutic outcomes [14]. Metastases to adrenal glands are much more common and are mainly of mammary, pulmonary, cutaneous or renal origin [17]. According to Hauch et al., malignant tumors have significantly more adverse outcomes (23.1\% vs. $13.2 \%$ ) [8].

Adrenalectomy may utilize several surgical approaches. Anterior laparotomy, open posterior retroperitoneal technique, anterior or lateral laparoscopy and lateral and posterior retroperitoneoscopic methods can be distinguished.

Anterior laparotomy provides good exposure and a wide operative field. It is therefore preferred in cases of large and/or malignant tumors. Myśliwiec recommends classical adrenalectomy for tumors bigger than $10 \mathrm{~cm}$ or infiltrating surroundings. Cooper describes longer survival of patients with ACC after an open procedure than in the endoscopic group [1, 6, 14, 17-19].

Despite its usefulness, the open approach is the most invasive and requires the largest incision. This may not be desired in patients with healing problems, such as older or obese patients or those suffering from Cushing's syndrome. Open adrenalectomy or conversion is associated with significantly greater perioperative morbidity, regardless of adrenal pathology [7, 12, 14, 17].

Very few studies compare posterior retroperitoneal open adrenalectomy with other approaches. Wong reports frequent occurrence of neuromuscular complaints and chronic back pain after such procedures, probably due to nerve damage [12].

Laparoscopic adrenalectomy is recommended for small benign adrenal masses $(<6 \mathrm{~cm}$ in diameter and $<100 \mathrm{~g}$ in weight) and surgical treatment of adrenal metabolic disorders. It is less invasive than an open procedure and thus enables the elderly, the obese or those suffering from circulatory diseases to qualify for treatment. Laparoscopic procedures are associated with lower postoperative morbidity (8\% vs. 13-20\%) [6, 11, 12, 14, 15, 17, 18].

Laparoscopy is contraindicated for tumors larger than $6 \mathrm{~cm}$, with suspicion of malignancy and in case of extensive adhesions from prior surgery. Laparoscopic resection of malignant masses increases the risk of intraoperative tumor spillage and incomplete clearance. Position of laparoscopic excision of adrenal malignancies is controversial and debatable [6, 11, 12, 14, 15, 17, 18].

Compared with the retroperitoneoscopic technique, laparoscopy offers a larger operative field and working space. Surgeons are generally more familiar with the anatomy and procedures concerning the peritoneal cavity than the retroperitoneal space and thus laparoscopic adrenalectomy is easier for them to learn. Laparoscopy is recom- 
mended in the case of a simultaneous abdominal operation, ectopically located adrenal glands and after nephrectomy on the ipsilateral side. Alesina pointed out that splenic injuries and intra-abdominal abscesses occurred only after laparoscopic procedures, while relaxation and/or hypoesthesia of the abdominal wall was observed only after retroperitoneoscopic ones $[2,7,12,15,17]$.

Minimally invasive retroperitoneal adrenalectomy is recently becoming the gold standard for surgical treatment of small $(\leq 6 \mathrm{~cm})$ and benign adrenal tumors, as well as isolated small solitary metastases. It provides the most direct access to the adrenal gland; hence there is no risk of injury to intraperitoneal organs. No bowel manipulation equals no postoperative paralytic ileus. The retroperitoneal approach requires no dissection of adhesions, which makes it suitable for patients with previous laparotomy. Bilateral adrenalectomy, even simultaneous, is possible without repositioning the patient. Insufflation of the retroperitoneal space has a lesser effect on hemodynamic and respiratory parameters than laparoscopy. High insufflation pressure (up to $28 \mathrm{~mm} \mathrm{Hg}$ ) provides better hemostasis due to compression of small vessels [2, 11, 12, 17, 18].

Retroperitoneoscopic adrenalectomy offers limited operative space, more difficult dissection and an inverted anatomic perspective. Therefore it is not suitable for larger tumors $(>7-8 \mathrm{~cm})$, patients with a short distance between the ribs and the iliac crest and/or high BMI, such as those suffering from Cushing's syndrome. It is also contraindicated if a simultaneous intra-abdominal procedure is necessary. In the event of major bleeding immediate conversion is impossible due to the patient's position. High insufflation pressure provokes ejection of catecholamines, increases end-tidal $\mathrm{CO}_{2}$ pressure, the risk of hemodynamic instability, deep venous thrombosis and gas embolism. Subcostal (Th12) nerve injury may occur in $9 \%$ of patients [1, 2, 11, 12, 17-20].

In conclusion, adrenal glands are surrounded by important anatomic structures (such as the colon, pancreas, spleen and diaphragm) that may be injured during careless dissection. That in turn may cause serious postoperative complications, requiring readmitting the patient and reoperation.

Complications after laparoscopic adrenalectomy can arise from the use of monopolar coagulation as well as the patient's position on the operating table. Videoscopic extraperitoneal procedures require higher insufflation pressure to create the working space than laparoscopy; this additional pressure may cause subcutaneous emphysema.

Complication rates depend on type of surgical approach, scope of operation and surgeon's case volume. Laparotomy is a significant risk factor for medical and overall problems. In our observations all non-surgical complications occurred after open procedures.

The second significant risk factor is the scope of the surgical procedure. Operations more expansive than just adrenalectomy are associated with much higher risk of postoperative medical complications.

Individual experience of the performing surgeon proved to be a risk factor for non-surgical complications. Procedures performed by surgeons with higher volume were associated with smaller risk of complications. Perioperative outcomes of residents are at least comparable to those of senior operators.

Patient's sex, type of pathology diagnosed by referring physician, bilateral procedure and side of operation are not statistically significant risk factors for complications.

Different types of complications are associated with right and left adrenalectomy. Risk of bleeding dominates on the right, while injury of surrounding structures occurs mostly on the left.

\section{Conflict of interest}

The authors declare no conflict of interest.

\section{References}

1. Harza MC, Preda AT, Ismail G, et al. Extent and type of surgery in adrenal masses. Acta Endo (Buc) 2014; 10: 404-13.

2. Cabalag MS, Mann GB, Gorelik A, Miller JA. Comparison of outcomes after laparoscopic versus posterior retroperitoneoscopic adrenalectomy: a pilot study. Surg Laparosc Endosc Percutan Tech 2014; 24: 62-6.

3. Dindo D, Demartines N, Clavien PA. Classification of surgical complications, a new proposal with evaluation in a cohort of 6336 patients and results of a survey. Ann Surg 2004; 240: 205-13.

4. Kiziloz H, Meraney A, Dorin R. Prognostic indices of perioperative outcome following transperitoneal laparoscopic adrenalectomy. J Laparoendosc Adv Surg Tech A 2014; 24: 528-33.

5. Porpiglia F, Fiori C, Bertolo R, et al. Mini-retroperitoneoscopic adrenalectomy: our experience after 50 procedures. Urology 2014; 84: 596-601.

6. Monn MF, Calaway AC, Mellon MJ, Bahler CD, Sundaram CP, Boris RS. Changing USA national trends for adrenalectomy: the influence of surgeon and technique. BJU Int 2015; 115: 288-94.

7. Alesina PF. Komplikationen der minimal-invasiven Adrenalektomie. Chirurg 2015; 86: 29-32.

8. Hauch A, Al-Qurayshi Z, Kandil E. Factors associated with higher risk of complications after adrenal surgery. Ann Surg Oncol 2015; 22: 103-10.

9. Seib CD, Greenblatt DY, Campbell MJ, et al. Adrenalectomy outcomes are superior with the participation of residents and fellows. J Am Coll Surg 2014; 219: 53-61.

10. Venkat R, Valdivia PL, Guerrero MA. Resident participation and postoperative outcomes in adrenal surgery. J Surg Res 2014; 190: 559-64. 
11. Paganini AM, Balla A, Guerrieri M, et al. Laparoscopic transperitoneal anterior adrenalectomy in pheochromocytoma: experience in 62 patients. Surg Endosc 2014; 28: 2683-9.

12. Wong A, Eloy JA, Liu JK. The role of bilateral adrenalectomy in the treatment of refractory Cushing's disease. Neurosurg Focus 2015; 38: E9.

13. Cesmebasi A, Du Plessis M, Iannatuono M, Shah S, Tubbs RS, Loukas M. A review of the anatomy and clinical significance of adrenal veins. Clin Anat 2014; 27 1253-63.

14. Kiernan CM, Shinall Jr MC, Mendez W, Peters MF, Broome JT, Solorzano CC. Influence of adrenal pathology on perioperative outcomes: a multi-institutional analysis. Am J Surg 2014; 208: 619-25.

15. Panumatrassamee K, Usawachintachit M, Ratchanon S, Santingamkun A. Transperitoneal laparoscopic adrenalectomy: a review and single-center experience. Asian Biomed 2014; 8: 533-9.

16. Castillo OA, Rodriguez-Carlin A, Lopez-Vallejo J. Complications associated with laparoscopic adrenalectomy: description and standardized assessment. Actas Urol Esp 2014; 38: 445-50.

17. Myśliwiec P, Marek-Safiejko M, Łukaszewicz J, et al. Videoscopic adrenalectomy - when does retroperitoneal seem better? Videosurgery Miniinv 2014; 9: 226-33.

18. Chai YJ, Kwon H, Yu HW, et al. Systematic review of surgical approaches for adrenal tumors: lateral transperitoneal versus posterior retroperitoneal and laparoscopic versus robotic adrenalectomy. Int J Endocrinol 2014; 2014: 918346.

19. Peyronnet B, Tanguy L, Corre R. Adrenalectomy for adrenal metastases: is the laparoscopic approach beneficial for all patients? Prog Urol 2014; 24: 1069-75.

20. International Classification of Diseases for Oncology (ICD-O-3). Code 8373/0: Adrenal cortical adenoma, clear cell. http://www.iarc.fr/, accessed online 30.07.2016. 